\title{
Holarchic HCI and Augmented Psychology (“AugPsy”)1
}

\author{
Suraj Sood \\ The Sirius Project, United States \\ thesiriusproj@gmail.com
}

\begin{abstract}
Consciousness enables experience, and each can be placed on a spectrum $[1,14]$. Experience is more robust and multidirectional, though the possibility exists for it to be bidirectional (particularly for the geometrician working along a line, but also generally when considering between two given options). Consciousness is synonymous informally with awareness. When one is conscious, they are aware, and vice versa. Awareness can be quantified in terms of being "greater" or "lesser". For example, one may be more aware of certain aspects of experience than others given selective attention.

Experience is the basic unit of analysis for phenomenology. While experience may be operationalized as qualia to address "what things are like" [20], the former may also be treated as a formal primitive. Phenomena are events as they appear to or present themselves for conscious perceivers. In ordinary use, experiences are assumed to be significant events or happenings.

Phenomenal experience is qualitative. It is characterized as such by description through adjectives (e.g., "good" or "bad”). Experiences can be categorized into types, e.g. into the learning kind (as in the "learning experience"). If an experience is rich, then it has richness that may be qualified-described further in terms of what makes it so-or quantified. Growth may result from the victorious experience. This is so in battle-based role playing games (RPGs), where successfully defeating one's opponent earns experience points that contribute to the possible level-up of one or more of the player's team members (as in Pokémon and Fire Emblem, two of the most popular Japanese action-adventure RPG series).

It is posited that the self, after being immersed in something greater than it, has potential to emerge greater than it was prior [2, 3]. Positive psychology recognizes such an immersed state as being one of flow or engagement. Subjective immersion [6] can be reported on to certain extents of meaningfulness and accuracy. Immersion can be qualified, e.g. via description of an activity's meaning to the human actor, or perhaps quantified. Perhaps the optimal flow experience is only quantifiable as being infinitely enjoyable, enriching, engaging, and/or meaningful, among other possible measures.
\end{abstract}

\footnotetext{
${ }^{1}$ Augmented psychology was argued for in [11] with the proposal of augmented mind, including augmented cognition, affect, and conation. AugPsy may also include augmented body [66], consisting of the deviceattaching human and their technologically extended self [67]. The AugPsy program propounded in this chapter is to be distinguished from Augmented Psychology as the psychological intervention using metaphorical experiences in virtual reality (VR), conceived on the basis of hypothesized "last frontiers" of neuroscientific research [71].
} 
Keywords: consciousness, experience, qualia, immersion, postphenomenology

\section{Introduction}

Consciousness enables experience. Consciousness and experience can each be understood as existing along a spectrum [1, 14]. (Affect can be as well, but the affective spectrum is devoted more exclusively to disorders [55].) Experience is more whole and multidirectional than consciousness, though the possibility exists for the former to be bidirectional (particularly for the geometrician working along a line, but also in general when deliberating between any two given options).

Consciousness is synonymous with awareness. When one is conscious, they are aware, and vice versa. Awareness can be quantified in terms of being "greater" or "lesser". For example, one may be more aware of certain aspects of experience than others, given selective attention. Exclusion of extraneous data, and the suppression or repression of cognition, affect, or conation, can each be psychological augmentative mechanisms if and only if they afford better task performance.

Experience is the basic unit of analysis for phenomenology. The central insight of phenomenology is that "pure experience is... a unity which is neither subject nor object but potentially both” ([44], p. 202). While experience may be operationalized as qualia to address "what things are like" [20], the former may also be treated as a formal primitive. Phenomena are events as they appear to or present themselves for conscious perceivers. In ordinary use, experiences are assumed to be significant events or happenings.

Phenomenal experience is qualitative. It is to be characterized as such by description through adjectives (e.g., "good” or "bad”). Experiences can be categorized into types, e.g. as of the learning kind (one's life may be full of "learning experiences"). If an experience is rich, then it has richness that may be qualified-described further in terms of what makes it so-or else quantified in terms of $\geq 0$ experiences.

Growth may result from victorious experience. This is so in battle-based role-playing games (RPGs), where successfully defeating one's opponent earns experience points that contribute to the possible level-up of one or more of the player's team members. This much is operative in Pokémon and Fire Emblem, two of the most popular Japanese action-adventure RPG series. 2

It is posited that the self, after being immersed in something greater than itself, emerges from immersion greater than before [2, 3]. Positive psychology recognizes

\footnotetext{
${ }^{2}$ Though the popular Yu-Gi-Oh! trading card game (TCG) does not have a corresponding game element of experience, it is relevant to HCI in ways distinct from the two other franchises mentioned. Specifically, $\mathrm{Yu}$-Gi-Oh! emphasizes technology heavily in its anime: this is exemplified in the character Seto Kaiba and his invention of "duel technology" in the form of the "duel disk". Using the duel disk allows players to play the card game while summoning realistic holograms of magic, "trap cards", and fantasy monsters that do battle. $\mathrm{Yu}-\mathrm{Gi}-\mathrm{Oh}$ ! is meta-technological in that, while interacting with one's computer (to watch the anime or play the franchise's video games), one also confronts technological possibilities not presently existent in the actual world.
} 
such an immersed state as being one of flow or engagement ("being one with the music3" when involved in a certain kind of activity). Subjective immersion [6] can be reported on to certain extents of meaningfulness and accuracy. Immersion can be qualified, e.g. via description of an activity’s meaning to a given human actor, or else quantified by answering how immersive said activity was or how many immersive experiences one or more subjects have had. Perhaps the optimal flow experience is just quantifiable as being infinitely enjoyable, enriching, engaging, and/or meaningful, among other possible measures. Related to flow as optimal experience is defining what constitutes optimal human-computer interaction (HCI). Examples of suboptimal HCI are illicit system hacking (e.g., of video game consoles like the New Nintendo 2DS), while optimal HCI may include practices like white hat (defensive) hacking in cybersecurity.

In this chapter, the above understanding of experience and consciousness will be related to formal-mathematical psychology. Related work leads to reported results of a semantic psychological study originating from experiments conducted in a virtual community of practice (VCoP) [56]. These experiments included neologism, conceptual innovation, and construct proposal, among other related activities (e.g., that of naming new fields and super-fields). Based on the semantic approach undertaken, three novel psychological constructs are generated. These are "memsight" and "foremory"-both denoting a hybrid memory-foresight construct - as well as "momeihor", a compromise term between the former two. Other constructs that follow from state-dependent memory are next generated, including trait-dependent, state-independent, trait-independent, state-interdependent, and trait-interdependent memories. “Associative identity superorder" and "innate helpfulness" follow from dissociative identity disorder (DID) and learned helplessness, respectively. (Identity itself is conceptualized holistically as a function of disposition, cognitive style, affect, judgment, and value [61].)

Following introduction to the above terms, it is argued that theoretical Type C-Z personality types follow from the Type A and Type B personality types. The Type C personality is regarded as either more passive than both Type A and B ones, or else as assertive (i.e., in between the aggressive Type A and passive Type B). Lastly, a program for generating psychological laws dubbed "psycholawgy" is proposed, along with candidate laws that could begin to populate this hitherto unfulfilled area of research. Each of the efforts undertaken in this chapter are important for human-computer interaction and augmented cognition in that - to understand the ideal mode of being-in-virtuality (including being-with-others, i.e. the Heideggerian Mitsein)—evaluations of both old and new constructs might be prerequisite for the discussion necessary. The present work also has broader potential value for the fields of psychology and philosophy.

\section{Related Work}

Person was formalized as a function of self and other; they were further granted to be romantic, existential, humanistic, chemical, environmental, hedonic and eudaimonic (happiness-seeking), conservative, and liberal [11]. These are in addition to persons being physical, chemical, biological, psychological, social, cultural, and spiritual (as

\footnotetext{
${ }^{3}$ Immersion in musical listening-along with the accompanying change in one's affective state to reflect the music's intended mood—can be viewed as an instantaneous flow state.
} 
explicated in Sood's [5] theory of reality). The holarchic, subjective-objective, holonic ontology of persons - a "psycho-ontology" using a novel mathematics to represent reality and mind formally - was enlarged. It is now granted that reality can be unconscious (i.e., dreamless deep sleep) ${ }^{4}$, subconscious (in hypnogogic and hypnopompic liminal states), conscious while in the default mode network (DMN), or superconscious when a peak-experience or self-transcendence [36] have occurred.

It remains an open question whether psychologists have fully accounted for both people and their situations. What determines their interaction? People and situations have power relative to one another. A person might overcome a challenging situation or be overcome by it. In the optimal case, people and situations have equal power relative to one another regardless of what determines the interaction. It may be hypothesized that what determines such an equal interaction is itself ideal.

Sood's multidimensional notion of person was expanded before being formalized in terms of more basic, psychological primitives. Such primitives have been introduced in previous works to address what has been called "the units of analysis problem in psychology” ([21], p. 177). However, Sood did not discuss the follow-up problem of quantifying psychology's basic units. (This problem is addressed in Section 4.1 of the present chapter.)

Sood's personology includes the following 27 properties of the human person 5:

1. Physical - People's bodies are composed of matter. Further, people interact with other physical objects.

2. Biological - People breathe, eat, and drink; and a great many of them have sex and reproduce.

3. Temporal - People are born, they live, and they die; they experience time.

4. Cultural - People are embedded in cultures characterized by unique but shared ways of being.

5. Social - People participate in societies consisting of concrete relations between themselves and others.

6. Economic - People are agents who trade goods and services with one another in marketplaces.

7. Technological - People invent and utilize tools to perform tasks they were previously unable or less able to accomplish.

8. Artistic - People express themselves through the creation of original works such as paintings and songs.

9. Intellectual - People aim to comprehend reality and achieve accurate understandings of it.

10. Moral - People have unique and shared ideas of wrong versus right action.

11. Spiritual - People seek enlightenment, wisdom, and contact with the divine or supernatural via practices such as meditation and prayer.

\footnotetext{
4 "Unconscious reality" was encountered in the name and lyrics of a song by the former pop-rock band Artist Vs. Poet. It is forwarded that psychological insight can be reached, and cognition thus augmented, via analysis of lyrics by such artists (including hard-rock band A Day to Remember, among many others).

${ }^{5}$ The human person has typically been discussed in theological, ethical, and philosophical contexts [37, 38].
} 
12. Religious - People worship what they deem as sacred (e.g., God or Gods; Goddess or Goddesses) through rituals and organized communion.

13. Political - People negotiate and have interests that are in line or at odds with those of others.

14. Athletic - Whether for fitness or organized play, people exercise their bodies and minds.

15. Professional - People work toward goals, including earning money and achieving satisfaction.

16. Recreational - People enjoy leisurely activities such as taking walks and attending parties.

17. Linguistic - People communicate via representational symbol systems characterized by semantics, syntax, and pragmatics.

18. Psychological - People have minds and engage in behaviors. More specifically, they think, feel, have personalities, interact with situations, are motivated, sense, perceive, experience, learn, and pay attention.

19. Romantic - People become emotionally involved with one another. Most get married.

20. Existential - People are responsible and free: they have psychological wills. ${ }^{6}$

21. Humanistic - People are creative, spontaneous, and active beings who contribute to the furthering of humanity.

22. Chemical - People are composed in part of physical reactions taking place throughout their bodies.

23. Environmental - People engage in a variety of ways with their surroundings.

24. Hedonic - People seek happiness in the form of pleasure.

25. Eudaimonic - People seek happiness in the form of fulfillment. ${ }^{7}$

26. Conservative - People live in accordance with rules and principles designed with security in mind.

27. Liberal - People live freely to maximize (e.g.) diversity, inclusion, and peace.

19 was added since it is subsumable under neither 5 (social) nor 9 (intellectual). (Contra-cognitivist models that view affect as merely a class of cognition: see [13] for a treatment of this perspective). Various existential theories of psychological will have been proposed in the past two centuries, ranging from Friedrich Nietzsche's "will to power” to Viktor Frankl's “will to meaning”. Will is used in the present context to refer

\footnotetext{
${ }^{6}$ This chapter's notion of existential humanness is intended to be fully compatible with Yalom's existential givens, including freedom, death, isolation, and meaning [45].

${ }^{7}$ An interesting question for affective HCI and positive computing, as well as for positive psychology, is whether the process of attaining eudaimonic fulfillment feels similarly to flow. Since cognition theoretically disappears during flow (as Seligman once claimed), does the same happen when one is maximally engaged in a flow activity that does not necessarily involve thought? If so, eudaimonia may be equated to Aristotelian flow. In any case, the question of where pleasure ends and fulfillment begins is a more general and worthy quantitative question to answer. Additionally, when non-cognitive, flow cannot be a form of augmented cognition (by definition), but may still be one of augmented psychology.
} 
simply to volition, i.e. purposive striving evidenced when one or more individuals decides on and commits to certain action.

Learning has been covered by Bandura \& Huston [24] and attention by philosophical, perceptual, and cognitive psychologists (e.g., William James). The formation of learned habits is essential for the development of procedural knowledge and memory. One interesting consideration regarding learning and attention is that "meta" or naturally-augmented versions of both learning and attention (as well as cognition) are at least conceivable, if not existent. Meta-learning occurs when one reflects on or operates on his or her procedural knowledge; meta-attention or meta-awareness occurs when we cognize over the nature of our awareness. Meta-awareness is the domain of phenomenology.

Marriage is an established social and religious (12) convention. Moreover, romantic being in the present sense is mostly meant as being affective (in the same sense as in 18: people "feel"). It could be expressed artistically (8) but is not reducible to such. 19 could thereby be viewed as a product of $5,8,9,12$, and 18 , though it need not be necessarily. 26 and 27 were meant not merely in their political senses, but more broadly to encompass human being and doing.

People were also granted to be inherently humanistic and environmental. For the theoretical psychologist, the latter is to be distinguished from persons' being situational as in 18. Varela et al. [48] propounded the original enactive framework unifying cognitive science with phenomenology, asserting that "the organism both initiates and is shaped by the environment" (p. 174). Sood [4] substituted "organism" and "environment" in this statement with "person" and "situation" respectively, asserting that doing so rendered his treatment more topically psychological. Lewin [22] formalized human behavior as

$$
B e=F[P, E]
$$

Where $B e$ equaled "behavior", $P$ equals "person”, and $E$ equals "environment". Lewin's statement reads "Behavior = Function of person and environment" (p. 878). Sood's [5] formalization of human behavior was assigned the variable $B$, which equaled $F[S m, R p]$

$$
B=F[S m, R p]
$$

Where $S m$ equals "stimulus” and $R p$ equals "response”. Sood revised Lewin’s behavioral formula to align more with traditional behavioristic psychology (viz., Skinner's [29]) and truncated the latter's $B e$ variable to simply $B$.

$S m$ could be regarded as analogous, if not identical, with $E$ in that for behaviorists like Skinner, stimuli were objects in the subject's surrounding (external) environment. For Rauthmann et al. [23], situations are composed partially of environmental cues that are physical, objectively quantifiable stimuli. While this framing suggests that the environment should be conceived as being part of situationality, for the present discussion, the interchangeability of $E, S m$, and situationality (formalized later in this chapter) is noteworthy. 


\subsection{Person-Computer Interaction (PCI)}

Psychological persons may be said to be either selves or others. Psychological notions of self and other pervade the existential psychological literature [33, 34]. Sood [1] formalized person-situation interaction as a complex, interdependent function of mental and behavioral structures (i.e., states and traits) and processes. He did so as follows

$$
[P, S]=F\left[S t_{(T, S e)}, P c\right]_{(M, B)}
$$

Where $P$ equals "person", $S$ equals "situation”, $S t$ equals "structure”, $T$ equals "trait", $S e$ equals "state", $P c$ equals "process", $M$ equals "mind" 8 , and $B$ equals "behavior" [20]. (Traits and states are treated as distinct types of psychological structures.) $[P, S]$ is a whole composed entirely of parts $S t_{M S e}, S t_{B S e}, S t_{M T}, S t_{B T}, P c_{M}$, and $P c_{B}$, which respectively denote "mental states", "behavioral states", "mental traits", "behavioral traits", "mental processes", and "behavioral processes". Informally, (3) reads: personsituation interaction is a function of mental and behavioral structures and processes. Such mental and behavioral structures may be either traits, states, or hybrid trates [11]. The use of trate over both state and trait would eliminate the need to use latter in formalisms such as (3).

The more direct formalization of $P^{9}$ was undertaken

$$
P=F[S l, O t]
$$

Where $S l$ equals "self" and $O t$ equals "other". Self has received a recent psychological treatment by Klein [31], where William James' classical notions of "self-as-known" and "self-as-knower" received updates to a more holarchic notion. Klein identifies two distinct kinds of selves from cognitive neuroscience and clinical case work involving memory and knowledge, in particular. Klein's epistemological self is "the self of neural instantiation: the neuro-cognitive categories of self-knowledge” (p. 20); his ontological self is "the self of first-person subjectivity...that consciously apprehends the content of the epistemological self" (p. 46). Klein's dualistic view of self may be characterized as holarchic-i.e., subjective-objective- to the extent that neuro-cognition is ontologically objective whereas first-person subjectivity is ontologically subjective. Dennett [32] also offered a novel theory of self, defining it as a center of narrative gravity, a "purely abstract object...[and] fiction". This treats self entirely as an ontologically subjective phenomenon.

Other is a concept that, while theoretically opposed from the notion of self, has received marginal attention from psychologists. The possibilities of the psychological

\footnotetext{
${ }^{8}$ Overmier and Lawry defined $M$ instead as “mediator” in the incentive motivation formula.

${ }^{9} \mathrm{~A}$ useful contribution to continental philosophy relevant to the present discussion of person would be the introduction of the concept "person-in-themself” (or "person-in-himself" and "person-in-herself"). This may exist as a counterpart to Immanuel Kant's "thing-in-itself", an object which appears to us but that we only can assume exists independent of our relation (e.g., observatory) to it. While person may be subsumed as a kind of noun along with thing, the former refers to an ontologically subjective rather than objective noun. Of course, based on the sub-discussion of self and other here, additional concepts may be introduced: "thing-in-itother" and "person-in-itother"; acceptance of the term "itother" (following from itself) would need to precede this.
} 
study of other open numerous such constructs. Hyphenated concepts and constructs for the same study of self include: self-relationship, self-possessed, self-hatred, self-disorder, self-compassion, self-confidence, self-control, self-distancing, self-doubt, self-efficacy, self-expansion, self-harm, self-reflection, self-suppression, self-determination, self-care, self-loathing, self-comparison, self-concept, self-esteem, self-handicapping, self-image, self-perception, self-regulation, self-reference, self-referential, self-actualization, self-transcendence, self-knowledge, self-ignorance, self-interest, self-report, self-replication, self-directed, self-talk, self-reliance, self-realization, self-defeating, self-concept, self-identify, self-as-known, self-as-knower, self-sabotage, self-aggrandizement, self-effacement, self-evident, self-love, self-consciousness, self-promotion, self-assessment, self-motivated, self-deception, and self-pity.

Based on the above, concepts and constructs for the study of other include: otherrelationship, other-possessed, other-hatred, other-disorder, other-compassion, otherconfidence, other-control, other-distancing, other-doubt, other-efficacy, other-expansion, other-harm, other-reflection, other-suppression, other-determination, other-care, other-loathing, other-comparison, other-concept, other-esteem, other-handicapping, other-image, other-perception, other-regulation, other-reference [74], other-referential, other-actualization, other-transcendence, other-knowledge, other-ignorance, other-interest [35], other-report, other-replication, other-directed, other-talk, other-reliance, other-realization, other-defeating, other-concept, other-identify, other-as-known, otheras-knower, other-sabotage, other-aggrandizement, other-effacement, other-evident, other-love, other-consciousness, other-promotion, other-assessment, other-motivated, other-deception, and other-pity. Further self and other concepts and constructs likely remain to be theorized on and scientized. The set of elements just delineated can be expanded based on interchanging suffixes, e.g. changing self-motivat-ed to self-motivat-ional. ${ }^{10}$

In the context of augmented cognition, the central role of the self who thinks (i.e., from Descartes' original cogito) is easily imagined and difficult, if not impossible, to successfully refute. Resolving the philosophical problem of other minds [30], which consists in answering whether we may come to know that other people's minds exist, would be tantamount to knowing how we could know of other people's cognitions (and affects and motivations in Sood's Platonic-Freudian model of mind). Such knowledge would be requisite for its instrumentalization; and, if technology consists in the instrumentalization of knowledge - not merely of information, which is truth value-neutralthen knowledge of other minds is requisite for any technology that would augment user cognition. The problem of other minds thus also represents a problem for the philosophy of HCI.

The problem of other minds may be attempted to be solved in one or more of the following broad ways:

1. Technological: Deeply immersive social networking. Ubiquitous communication and interaction between agents via, e.g., heavily networked virtual reality (VR) simulation.

\footnotetext{
${ }^{10}$ Concepts following from (3)-(4) include: personal situation; situational person; personal self; personal other; situational self (i.e., who one is in a given context or setting); and situational other.
} 
2. Spiritual: Collective immersion in flow, peak, religious, or meditative experiences. Transpersonal overcoming of the manifest, illusory self-other distinction; feeling one with the world or universe as either a state (e.g., the peak experience [36]) or trait.

3. Biopsychosocial: Empathy, abductive inference, and conviction or faith in the existence of other minds.

The technological possibility is relevant for human-computer interaction, and more specifically for the projects of augmented cognition and psychology. (Relatedly, the project of augmented cognition may be defined as that of aligning thought with reality.) The biopsychosocial possibility above refers to the theory of mind phenomenon, where social agents hold intuitive beliefs in the existence of other minds.

Knowledge is understood here as a form of cognition represented in one's mind or being enacted procedurally via the skilled use of one's body. ${ }^{11}$ In either case, knowledge is encoded in an embodied, neurocognitive substrate. Representing knowledge via formal syntax and operations is the domain of mathematical logic, which also extends into computation primarily in the form of discrete logical operations determined by the programmer. ${ }^{12}$

\subsection{The Platonic-Freudian Model of Mind}

Sood [5] formalized $M$ mind as a portion of $\psi$, psychology (denoting the field of psychology, including its two most eminent and high-level, modern topics of study). He did so as follows

$$
\psi=F[M, B]
$$

Where $B$ equals behavior. Sood's formalism was disciplinary in nature; person-situation interaction (with $(M, B)$ operating as a subscript to $\left.\left[S t_{(T, S e)}, P c\right]\right)$ could just as easily have been set equal to $\psi$. In any case, $M$ was next formalized as follows

$$
\left.M=F\left[(A, C, M v)_{(U-,} S b-\right) C S\right]
$$

Where $A$ equals "affect”, $C$ equals "cognition”, $M v$ equals "motivation”, $U$ - equals "un-", $S b$ - equals "sub-", and $C s$ equals "consciousness". According to the right portion of (6)'s subscript, each of these elementary mental phenomena may be either unconscious, subconscious, or conscious. (8) yields the following nine constructs: "un-

\footnotetext{
${ }^{11}$ Procedural memory consists in the storage of and retrieval from embodied knowledge. An interesting consideration is its connection with expert intuition, which does not yet seem to have been rendered explicit. Procedural memory and expert intuition draw from one’s stored set of embodied "know-how" and "knowthat”, respectively.

${ }^{12}$ Related to the formal representation of knowledge is the question of how to quantify knowledge. One may answer this by counting all propositional statements that an agent knows to be true.
} 
conscious affect”, "subconscious affect”, and "conscious affect"; "unconscious cognition", "subconscious cognition", and "conscious cognition"; and "unconscious motivation", "subconscious motivation", and "conscious motivation". Any of these constructs could informally be considered subminds in a manner analogous to how each of the five-factor model's traits (Openness, Conscientiousness, Extraversion, Agreeableness, and Neuroticism) could be regarded as subpersonalities of a given person's overall personality.

Formula (6) drew from Freud's topographical model of mind [18] on one handwhere mental content passes between the unconscious and conscious sub-minds via the intermediary subconscious - and Revelle's recent attempt to synthesize Plato's tripartite model of mind (consisting of precursors for affect, cognition, and motivation) into a formal personality framework [19]. (6) is presumed to be compatible with Mischel \& Shoda's [43] "cognitive-affective system theory" of personality (p. 246).

The fusion of (2), (3), and (6) was undertaken

$$
[P, S]=F\left[S t_{(T, S e)}, P c\right]_{\left[(A, C, M v, B)_{(U-, ~ S b-) C S}\right.}
$$

(7) reads: Person-situation interaction is a function of unconscious, subconscious, and conscious affective, cognitive, motivational, and behavioral traits, states, and processes. $B$ here was not part of Sood's original Platonic-Freudian model of mind, nor does (7) need to imply that it now is. It has been added to (7) (and subsequent invocations of $F\left[S t_{(T, S e)}, P c\right] \ldots$ ) given its historical closeness with $M V$ (see the conation concept as in Plato's work [25]), and to accommodate Maslow's view of behavior almost always requiring motivation in order to occur. The tripart primitives listed in Table 1 follow from the compound psychological primitives named between (6) and (7).

The mathematical-theoretic approach to psychology undertaken [1, 2] requires an expansion of Freudian topography. Specifically, if unconsciousness is zero (0) awareness; subconsciousness is half (0.5) awareness; and consciousness is full (1) awareness, then mathematically, one could speak equally of negative subconsciousness and consciousness: -0.5 and -1 awareness, respectively. 13 Numerous typologies of consciousness exist. Subconsciousness and unconsciousness may be considered grades of consciousness, but as with experience, one may speak of kinds of consciousness, such as technological and literary consciousnesseses. 14

Sood [1, 2] formalized the sub-primitives of Table 1's triads into his person-situation and mind formulae but neglected to explicate them rigorously. Affect is a "a non-conscious experience of intensity...a moment of unformed and unstructured potential" [40]. It "cannot be fully realized in language" and "is always prior to and/or outside of consciousness". It is "the body's way of preparing itself for action in a given circumstance by adding a quantitative dimension of intensity to the quality of an experience".

\footnotetext{
${ }^{13}$ The unconscious sub-mind can be formally defined as the set of all holons that exist outside of awareness.

${ }^{14}$ [51] describes eight kinds of consciousness, including organism, control, intentional, state/event, reportable, introspective, subjective, and self-consciousnesses. Introspective consciousness is speculated to be a "special case" of intentional consciousness and is proposed to explain state/event consciousness (p. 4).
} 
Table 1. Tripart primitives of Sood's Platonic-Freudian model of mind ${ }^{15}$

\begin{tabular}{|c|c|c|c|}
\hline Structures and & \multicolumn{3}{|c|}{ Freudian topography } \\
\hline & $\begin{array}{l}\text { CsASe: } \\
\text { Conscious affec- } \\
\text { tive state (e.g., } \\
\text { palpable moods; } \\
\text { feelings "of the } \\
\text { moment") }\end{array}$ & $\begin{array}{l}\text { CsMvSe: } \\
\text { Conscious motiva- } \\
\text { tional state (e.g., real- } \\
\text { izing to reach a goal } \\
\text { state or overcome a } \\
\text { given situation) }\end{array}$ & $\begin{array}{c}\text { CsCT: } \\
\text { Conscious cognitive } \\
\text { trait } \\
\text { (e.g.: woke } \text { wopn- }^{16} \text { Open- } \\
\text { ness") }\end{array}$ \\
\hline \multirow{3}{*}{$\begin{array}{l}\text { Platonic triad } \\
\text { (including } M v \text { in- } \\
\text { stead of } B \text { ) }\end{array}$} & $\begin{array}{l}\text { CSAT: } \\
\text { Conscious affec- } \\
\text { tive trait (e.g., } \\
\text { woke Neuroti- } \\
\text { cism) }\end{array}$ & $\begin{array}{c}\text { CsMvT: } \\
\text { Conscious motiva- } \\
\text { tional trait (e.g., } \\
\text { woke Conscientious- } \\
\text { ness) }\end{array}$ & $\begin{array}{l}\text { CsCSe: } \\
\text { Conscious cognitive } \\
\text { state (e.g.: being } \\
\text { pensive; being mo- } \\
\text { mentarily lost or ab- } \\
\text { sorbed in thought, } \\
\text { i.e. introspective, re- } \\
\text { flective, ruminative, } \\
\text { imaginative, cogita- } \\
\text { tive; daydreaming) }\end{array}$ \\
\hline & $\begin{array}{l}\text { SbCsCSe: Subcon- } \\
\text { scious cognitive } \\
\text { state (e.g., REM- } \\
\text { dreaming) }\end{array}$ & $\begin{array}{c}\text { SbCsASe: } \\
\text { Subconscious affec- } \\
\text { tive state } \\
\text { (half-awareness of } \\
\text { mood, fleeting feel- } \\
\text { ings or emotionality) }\end{array}$ & $\begin{array}{c}\text { SbCsMvSe: } \\
\text { Subconscious moti- } \\
\text { vational state }\end{array}$ \\
\hline & $\begin{array}{c}\text { SbCSCT: } \\
\text { Subconscious cog- } \\
\text { nitive trait (e.g., } \\
\text { Jungian/Myersian } \\
\text { "iNtuitive" type) }\end{array}$ & $\begin{array}{l}\text { SbCsAT: } \\
\text { Subconscious affec- } \\
\text { tive trait (half-aware- } \\
\text { ness of Neuroticism } \\
\text { or Extraversion - En- } \\
\text { thusiasm) }\end{array}$ & $\begin{array}{c}\text { SbCSMvT: } \\
\text { Subconscious moti- } \\
\text { vational trait }\end{array}$ \\
\hline
\end{tabular}

${ }^{15}$ References to constructs of the five-factor model of personality (a.k.a. the "Big Five”) are derived from [39].

${ }^{16}$ Woke was defined formally in [11] as meaning "subjectively self-aware". This could be expanded into "a trate of being subjectively self- or other-aware: often, but not necessarily, as such awareness is of perceived social injustice”. 


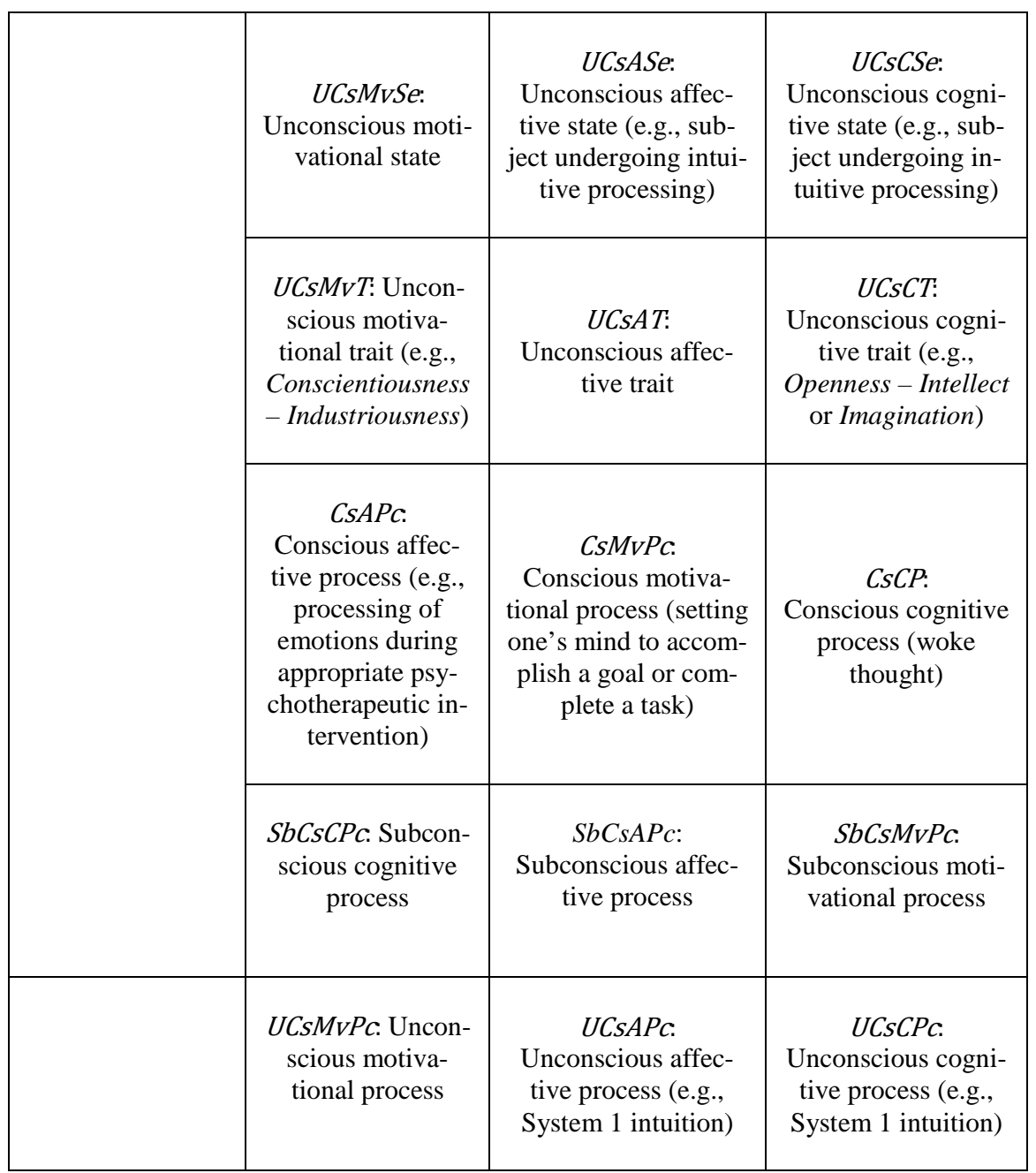

Starting with Kahneman and Tversky [26], cognition in modern psychology has frequently been defined as consisting of Systems 1 and 2. In this “dual-process” theoretic model, System 1 consists of thought that is fast, instinctive, affective, and unconscious. (Intuition is an unconscious process, but its outputs-occurring as insight, e.g. realized by a subject in an "aha!" moment-are conscious.) System 2, on the other hand, consists of slower, more deliberative, logical, and conscious cognition. A triple-process theory of love, in which such a dual-process one consists of System 1 romantic love and System 2 care, would be a novel and valuable contribution to the cognitive psychology of love. ${ }^{17}$ Such a theory would build upon theories positing that romantic love

\footnotetext{
${ }^{17}$ Further, speaking of the "head" and "heart" in metaphorical terms could lead to the quantification of just how "ahead" (i.e., mature) cognition or affect might be in relation to the other (assuming the metaphor holds literally).
} 
consists of joy, interest, and sexual arousal [58], while love itself consists of passion, commitment, and intimacy [59]. ${ }^{18}$

Motivation has been defined differently by theorists. The basic question for the science of motivation is why beings (viz.: humans, animals, and/or robots; possibly aliens) do what they do. Anthropological theories of motivation abound. In psychology, prominent such theories are ones of drive-reduction, evolutionary, and optimal arousal. A parsimonious, complete theory of motivation would minimally need to answer the questions of why such beings want to, should, need to, and do carry out their behaviors.

Maslow developed the hierarchy of needs. His theory posits that humans successively fulfill needs of varying classes [27]. He believed that motivations could be meaningfully separated into groups based on two criteria: 1) which of them must be acted upon first in order for a person to survive, and 2) which are necessary to act upon to reach self-actualization. Maslow and Horney considered self-actualization respectively as a syndrome and trait of neurotic personalities, reflecting the state of psychological theory during the early/mid-20 $0^{\text {th }}$ century as psychoanalytic and clinical more so than positive: i.e., being more interested in human growth and potential, flourishing, and well-being.

In decreasing order of their relative degrees of necessary fulfillment, Maslow's motivations were physiological, safety, love, esteem- “D-needs”, i.e. deficiency needs or survival needs-and self-actualization needs, i.e. "B-needs" or being needs (perhaps more accurately re-termed "B-wants"). Still, the question of how motivations such as these interact-both with one another and with other factors (cognitive, affective, behavioral) — has not yet been answered. For Maslow, motivation was almost always necessary for behavior; additionally, he believed that more than one motivation typically figures into a single behavior ([27], p. 370). The Maslowian science of motivation must work first from behavior to motivation, and possibly afterward, from motivation to other, equally-fundamental psychological phenomena (viz., affect and cognition).

Maslow [27] stated that "any conscious desires (partial goals) are more or less important as they are more or less close to the basic needs [of Maslow's hierarchy]" (p. 384). Since Maslow recognized some fundamental connection between desires and goals, it follows from an earlier statement he made-that "conscious, specific, localcultural desires are not as fundamental in motivation theory as the more basic, unconscious goals” (p. 370) — then unconscious wants will always be closer to basic human needs than will conscious ones.

The theory that unconsciousness is more influential motivationally than consciousness goes back to at least Freud; this theory may be more amenable to a truly scientific analysis today. There remain the scientific questions associated with motivation's operationalization. Two such questions may be posed. First: How do we identify distinct motivations as such — both in terms of their relatively more autonomous properties, and

\footnotetext{
${ }^{18}$ A Platonic theory of love can also be added. In such a model, love can be conceptualized as being affective (consisting of emotions like joy), cognitive (containing fond thoughts of the object of love), or conative (demanding action on the part of the lover to better the state of the loved object).
} 
their interactions in a person or persons' overall motivational system(s)? It may be easiest to start with the more basic but core concept of motive. Different motives for behavior exist: people do things to reduce drives, adapt, or achieve optimal arousal. These may be taken to be the human's most fundamental motivations after the fulfillment of D-needs. Motive illustrates the utility of hermeneutic methods applied in psychology, viz. within phenomenology. Conscious motives can be interpreted on at least three levels: first-, second-, and third-person [48-50].

First-, second- and third-person approaches in cognitive science have been applied only to consciousness. It remains to be elucidated theoretically whether a "zeroth-person" approach could be suited to the study of unconsciousness. A zeroth-person approach would precede the possibility of the first-person one, thus being appropriate for the study of preconscious trates. The zeroth-person would be the Homo sapiens' most recent ancestor who lacked consciousness enabled by a central nervous system (CNS). Similarly, one could also speak of a "half-person" approach to the study of subconsciousness, possibly referring to half the normal degree of human consciousness. Typing in this manner also allows for the possibility of consciousness containing an indeterminate number of possible degrees, i.e., a trigonometry of visual consciousness.

The first-person perspective interrogates or defines motives to oneself: i.e., I did $\mathrm{X}$ because X or Y. (One may be motivated by means or ends.) The first-person analysis of motive is thus personal and (at least ontologically) subjective. The second-person level involves how others frame our motives: "He or she did X because X or Y". This perspective is interpersonal and (at least ontologically) intersubjective. (Ontological intersubjectivity follows from Searle's treatment [53] considered alongside Wilber's metaphysical ontology [54].) Finally, third-person perspectives are more likely to appeal to physical, chemical, or biological (ontologically objective) motives. In this case, drive-reduction and optimal arousal theories may be favored more readily. Such a perspectival analysis complicates the fact already acknowledged that motivation may be unconscious, subconscious, conscious, negative-subconscious, or negative-conscious. For example, one agent may be unconsciously motivated at the first-person level, while another agent might be conscious of the former's motivation at the second- or thirdperson level(s).

A second question for motivational science is: How do motivations interact with other psychological phenomena like cognitions and affects? Motivation may be felt in response to a desire. For example, if one desires a long-term mate, one could become motivated to seek out and become involved with a promising candidate. One may then plan how to go about getting to know said candidate sufficiently to evaluate long-term mating potential. Considered in this way, the search for a long-term romantic partner includes affective, motivational, and cognitive factors and processes that follow from one another (possibly, in this order). ${ }^{19}$

\footnotetext{
${ }^{19}$ Related to the topic of long-term romantic partnership is the more general role of affect in interpersonal relations. One relevant question is: Can we behave to determine—rather than merely influence-a given being's affective trate? If so, the door is opened to affective governance in everyday contexts. Such social engineering in the form of institutionalism would seek to negate the neoliberal view of the autonomous subject, where individuals are solely self-responsible [57].
} 
Kelly [18] considered laziness, appetite, and affection as motivational concepts. Kelly understood motivations as being parts of greater systems of construction evidenced by individuals (e.g., through dialogue). Considered this way, motives can be thought to play out within proximity to beliefs. However, "appetite" is closer to one of Maslow's basic needs and is also something of a raw instinctual property characterizing a living being's consumptive capacity with respect to a suitable object Y (e.g., food). Kelly also provided a more historical framing of motivation in terms of the synonymous triads of "cognition, conation, and affection", "intellect, will, and emotion", and (in more modern terms) "thought, action, and feeling" (pp. 68-9).20 Motivation, then-to the extent that it is will manifest in one's action - may be determined as such in reverse fashion from behaviors. However, Maslow [19] asserted that "Motivation theory is not synonymous with behavior theory... While behavior is almost always motivated, it is almost always biologically, culturally, and situationally determined as well” (p. 371).

Maslow's hierarchical view of motivation has been contrasted with Kelly's more dynamic one [11]. For Kelly, a more socially-enactive, cognitive path would render motivation a clearer construct for psychological scientists (including personality psychologists) to operationalize. Regarding the possibility of unmotivated behavior, Maslow stated that "expressive behavior is either unmotivated or...less motivated than coping behavior" ([28], p. 138). Expressive behavior is unconscious (UCsB) while coping behavior is conscious (CsB).

\subsection{The $S$ Equation}

The psychological situation concept has been lamented by Rauthmann et al. [23] as being used often "haphazardly, ambiguously, [and] inconsistently" in the literature (p. 363). To ameliorate this, these authors proposed "three different basic kinds of situational information: cues (composition information), characteristics (psychological meaning information) and classes (category information)" (p. 363). Cues represent "physically present, scalable and (relatively) objectively quantifiable stimuli" (p. 364). Characteristics capture the "psychologically important meanings of perceived cues, thus summarizing a situation's psychological 'power”' (p. 364). Finally, classes represent "abstract groups, or types, of situations” (p. 364).

The formalization of Rauthmann et al.'s situation framework was undertaken in [11]

$$
S=F[C u, C h, C e]
$$

Where $S$ equals "situation", $C e$ equals "class", $C h$ equals "characteristic", and $C u$ equals "cue". Given (3), (4), and (8) and the transitive property, (9) resulted

$$
[P, S]=[F[S l, O t], F[C u, C h, C e]]
$$

By (9), person-situation interaction was extended as a function of the interaction between selves and others with cues, characteristics, and classes.

\footnotetext{
${ }^{20}$ In [64], it is noted that affection, cognition, and conation correspond respectively with pathos, logos, and ethos. It may be considered whether the respective groupings, when included equally by a given mind or persuasion and transcended, yield a super-mind or super-persuasion.
} 
The following equation fused (2)-(8), above

$$
\begin{aligned}
& {[F[S l, O t], F[C u, C h, C e]]=} \\
& \left.F\left[S t_{(T, S e)}, P c\right]_{\left[(A, C, M v, B)_{(U-,} S b-\right) C S}\right]
\end{aligned}
$$

(10) read: Person-situation interaction as a function of self and other-cue, characteristic, and class interaction is a function of unconscious, subconscious, and conscious affective, cognitive, motivational, and behavioral traits, states, and processes. It is a meta-psychological statement incorporating the major psychological constructs considered here and in previous work. The system of functions formulated in equations 1-10 is recursive in being self-referential: each function is definable in terms of itself. ${ }^{21}$

As an example of recursion in HCI, equations 1-10 also point to the inherent reflexivity of HCI work (e.g., programming) and research (e.g., browsing). HCI is inherently reflexive to the extent that the humans involved work on or with computers, thus instantiating human-computer interaction while operating in to said field. HCI in general may be said to be recursive if and only if (iff) its work refers explicitly to the reflexive loop just mentioned.

\section{Semantic Averaging and Enumeration: Novel Concepts and Constructs}

The motivation for proposing novel concepts and constructs is important for any psychological science to clarify. Kukla [52] describes the process of conceptual innovation in psychology. At times, it may prove necessary for the augmented cognition researcher to assess the value of existing concepts and constructs in terms of their utility or semantics (as well as their historical relevance). Certain constructs may have fit better in a previous iteration of science with respect to their "discursive roles", i.e., how they were taken up in dialogue.

An example of a psychological concept that arguably never evolved into a construct is Plato's notion of conation. Whereas by it, Plato referred to something exactly between the modern-day understandings of motivation and behavior, there is no wellestablished science of conation itself. Given the respective states of our psychological sciences of motivation and behavior, as well as the potential value of understanding these two phenomena together, a science of conation's value would unite two fundamental psychological phenomena through a common construct.

The above may apply in the case of constructs like foresight [15] and memory, both of which are studied in modern psychology. Following from the enumeration of several novel terms for the psychologies of self and other [11], otherish is proposed as

\footnotetext{
${ }^{21}$ In the spirit of (4) and its description in this chapter, it is encouraged that future studies consider an "otherreferential” counterpart to the concept of recursion. In an other-referential formal system, functions or other mathematical objects would be definable as other terms occurring within a given universe of discourse. In terms of mathematical equations, such reverse-recursion (“cursion”) could simply refer to one value on a side of an equation equaling values on the other.
} 
a counterpart to selfish (for philosophical psychology, in particular [16]). Whereas being selfish can be defined as being excessively self-interested, to be otherish would be to act excessively other-interested. This may be applied to understanding scenarios like the prisoner's dilemma [17] in which agents should act to balance self- and other-interest. Superconcepts containing two or more subconcepts [62] are also considered.

\subsection{Semantic Averaging: "Foremory" and "Memsight"}

Based on a shared neuropsychological basis [15], one may wish to understand memory and foresight in terms of a common unit. In such a case, one may apply a "semantic averaging" method to both constructs in the interest of generating one or two novel constructs. A pseudo-mathematical approach may be as follows

$$
\left[\frac{\text { Foresight }+ \text { Memory }}{2}\right]=\{\text { Foremory, Memsight }\}^{22}
$$

Like the research summarized in Section 2, foresight and memory may be assigned variables. Foresight can be denoted by $F s$ and Memory by $M o$

$$
\left[\frac{F s+M o}{2}\right]=\{\text { Foremory, Memsight }\}
$$

If there is sufficient utility in using either foremory or memsight to denote the hybrid memory-foresight phenomenon, researchers may choose either. It is recommended that only one be committed to ensure that studies of it proceed using a shared term. Foremory or memsight can be used, or else semantic averaging can be applied to these two terms as in the following subsection.

\subsection{Foremory and Memsight: "Momeiohr"}

Memsight and foremory theoretically both refer to the hybrid memory-foresight or foresight-memory construct. Which is used may depend on the subjective position of a researcher as being interested in either of memory or foresight more than the other. If memory is preferred, memsight may be decided on; and if foresight is preferred, foremory may be chosen.

If memory and foresight are valued equally in a study of their joint construct, one may apply sematic averaging to memsight and foremory as follows

$$
\left[\frac{\text { Memsight }+ \text { foremory }}{2}\right]=\text { Momeiohr }
$$

\footnotetext{
${ }^{22}$ The neologism of psychological portmanteaus like foremory and memsight can be traced historically to [60] with the coinage of "idiothetic". As a portmanteau of idiographic and nomothetic, the idiothetic approach to personality seeks a middle ground between qualitative case study and quantitative population analysis.
} 
Momeiohr (pronounced moe-may-oar) was generated by selecting the first letter of memsight, the second one of foremory, the third one of memsight, the fourth of foremory, and so on until the final letter being borrowed from foremory. Privilege was given to the first letter of momeiohr being $m$ given its status as the first letter of memory, which preceded foresight as used here in psychological theorizing.

\subsection{Trate-(In(ter))Dependent Momeiohr}

From state-dependent memory (the phenomenon of greater recall occurring in situations similar to when information was absorbed) as well as Stephen Covey's lifespan developmental philosophy of increasing interdependence from previous independence and dependence [13], several novel concepts can be derived. These include:

- Trait-independent memory (T-IdM)

- State-independent memory (S-IdM)

- $\quad$ Trait-dependent memory (T-DM)

- $\quad$ State-dependent memory (S-DM)

- $\quad$ Trait-interdependent memory (T-ItdM)

- State-interdependent memory (S-ItDM)

- $\quad$ Trait-independent foresight (T-IdF)

- $\quad$ State-independent foresight (S-IdF)

- Trait-dependent foresight (T-DF)

- $\quad$ State-dependent foresight (S-DF)

- Trait-interdependent foresight (T-ItdM)

- $\quad$ State-interdependent foresight (S-ItdF)

Lifespan considerations are relevant here. For example: for $1^{\text {st }}$-world citizens, does the average person start dependent (ideally, ages 0-33), then become more independent (33-66), and finally interdependent (66-100)?

\section{4 “Associative Identity Superorder" and "Innate Helpfulness"}

Superconcepts consist of two or more subconcepts. A novel example would be the superconcept of an "inner child-adult self", which may be operationalized as a loop (thus rendering it a construct). This superconcept combines the subconcepts of inner child and adult self, which have been discussed in relation to one another in the context of abandonment grief [63].

"Associative identity superorder" can be derived from dissociative identity disorder (DID). Associative identity superorder (AIS) can be defined as having the parts of one's identity reinforce one another in a way that boosts one's well-being. "Innate helpfulness" can be derived from learned helplessness [72]. If learned helplessness is the acquired reaction to a hopelessly harmful situation, innate helpfulness could be the unlearned response to hopefully beneficial persons.

Festinger's cognitive dissonance, rather than referring to a logically inconsistent set of $2+$ cognitive propositions, is technically cognitive-behavioral dissonance [7]. Ac- 
cording to [7]: "[Dissonance], that is, the existence of non fitting relations among cognitions, is a motivating factor in its own right. By the term cognition...[Festinger meant] any knowledge, opinion, or belief about the environment, about oneself, or about one's behavior. Cognitive dissonance can be seen as an antecedent condition which leads to activity oriented toward dissonance reduction just as hunger leads to activity oriented toward hunger reduction" (p. 3). Behavioral, motivational, and affective dissonances follow from cognitive dissonance. Behavioral dissonance consists of conflicting behaviors: e.g., "hot-and-cold" relationship ${ }^{23}$ styles. Motivational dissonance consists of ambivalence in the form of "I want to/should/must" vs. "I do not want to/should not/must not", e.g. when faced with a possible task. Affective dissonance can take the most basic form of "I like it" vs. "I dislike it", pertaining to ambivalence regarding one's feelings (possibly toward one's intimates [69]).

Naturally, positive variants of the above concepts can also be proposed. Affective consonance, i.e. agreement between affects, consists in either total liking or total disliking. Behavioral consonance can be defined simply as being in flow, totally immersed in an activity [6]. Motivational consonance may consist of total (un)wanting. Finally, cognitive consonance consists of logical consistency within one's mind.

\subsection{Type $\{$ A, B, ... Z $\}$ Personalities and Ideal Persons}

Type A and B personality types exist in both the literature [40] and common parlance. Type A individuals are defined as overtly aggressive; Type B individuals are behaviorally passive. The Type A-B hybrid personality may be considered optimal, ideal, and balanced. Neurotic Type C and D personalities have also been posed [70]. Theoretically, one could speak of personality types E-Z, though all such types would need to be defined in terms of their proneness to cardiac disease as the original Type A and B were.

One may speak of ideal psychological persons in terms of ruling style, communication style, and personality. The ideal ruler from a psychological view is authoritative in the first place. Any given ideal person, particularly from the vantage point of American psychology, is assertive rather than passive or aggressive. The ideal personality from the perspective of the five factor model may be interpreted as being Open, Conscientious, Extraverted, Agreeable, and Emotionally Stable, possibly scoring in the middle of these scales.

\footnotetext{
${ }^{23}$ Also of relevance to relationships vis-à-vis augmented cognition is the former’s increasing technological mediation. Such mediation takes the forms of text, voice, and video chats, messaging, and meetings. A typology may be sketched out where long-distance relationships are assumed to be the most technologically mediated, necessarily relying on the aforementioned communication channels.
} 


\section{Psychological Laws ("Psycho-law-gy")}

A successful science generates laws governing the phenomena of interest. To date, psychology has not successfully done such. An example of a psychological law is as follows: Personality types, as in the popular Myers-Briggs Type Indicator (MBTI), are characterized by the more frequent presence of certain personality traits. Such statements can prevent conflations of personality constructs from differing models (e.g., MBTI vs. five factor model or "Big Five").

Below is an attempt to established psychological axioms inspired by the formal mathematical approach summarized in Section 2. Such an attempt is intended to build upon the kind of psychological law (what can henceforth be referred to as "psycholawgy") attempted in the preceding paragraph.

1. Persons interact with situations. This is taken for granted in the study of personsituation interaction.

2. Person-situation interaction consists of mental and behavioral structures ("trates", i.e. state-trait hybrids or fusions) and processes.

3. Mental trates are affective, cognitive, and conative. Conation can refer to behavioral motivation or motivated behavior. It is a preexisting hybrid concept uniting modern psychology's constructs of behavior and motivation. Motivated behavior is not expressive. Expressive behavior is not engaged in to cope with reality. Rather, it is done for its own sake: expressive behavior is self-justified.

4. Behavior is affectively and cognitively motivated. This is reflected in the formalism $B=F\left[M v_{A, C}\right]$, i.e., behavior is a function of cogfective (affective-cognitive) motivation.

The principal questions for conative (motivational-behavioral) philosophy to ask, and for conative science to answer, are: 1) Why do beings do what they do? And 2) How do they do such? 1 must be answered in terms of psychological beings' guiding motives. 2 would be answered in terms of behavioral mechanisms, i.e., stimulus-response $(S m-R p)$ interaction and reinforcement-punishment dynamics. Behavioral reinforcement strengthens the frequency or intensity of a given set of action(s), while such punishment weakens either or both.

The "triple-process theory" follows from [8], which expanded the dual-process theory of cognition $[9,10]$ consisting of the intuitive System 1 and analytical System 2. Per [11]'s neologized construct cogfect (see 4 in this section), and the fact intuition is treated as both cognitive and affective (hence its being "cogfective"), triple-process theory is transitorily cogfective. There is good reason to reject cognitive psychology's claim to affect, particularly if Hume's [12] adage that "reason is...the slave of the passions” holds interpersonally (or epistemic- intersubjectively-i.e., irrationally and ineffably). However, System 3 decision-making combining intuitive affect ${ }^{24}$ and analytical cognition is also conative in its motivational underpinning and behavioral output.

\footnotetext{
${ }^{24}$ See [42] for a discussion of intuitive cognition.
} 
Such decision-making involves determining a desired, existential (mid- to long-term) goal state. ${ }^{25}$

\subsection{Quantification of Psychological Units}

The formulation of psychological laws can benefit from the quantification of psychological variables or constants. In the case of equation (6), cognition $C$, affect $A$, and motivation $M_{V}$ were included as sub-domains of mind $M$. Along with behavior $B$, the quantification of these four factors is straightforward. Once they are identified as such, one may count cognitions, affects, motivations, behaviors, and minds. Cognition is reducible to thought: thus, once one has counted discrete thoughts, the quantification of cognition can be undertaken. Thoughts may be considered as either "complete" or "incomplete". Complete thoughts, i.e. complete cognitions, consist of verbal thoughts taking the form of complete grammatical sentences. A complete cognition in the English language may be: I am hungry for a burrito. In contrast, an incomplete cognition in English may be: want burrito. Incomplete cognitions may in fact be viewed as more affective: they may express a desire of the subject, possibly of a stronger nature given their incompleteness. If this view is adopted, affects can be quantified as incomplete cognitions, though the question of whether compete versus incomplete affects exist may arise.

Behaviors are easy to quantify so long as it is agreed what constitutes a discrete one. A discrete behavior may be as general as "standing". One may count the instances of standing that occur across a given set of subjects within a time range and count these as one kind of behavior. Behavior may be quantified in terms of its types, or more generally based on the number of times a subject is observed to respond to a stimulus. Here as before, responses $R p$ and stimuli $S m$ may be quantified by themselves, but as the parameters governing behavior. Defined in these terms, a behavior is governed by a distinctly-bonded pair between stimulus and response.

\section{Discussion}

One obvious limitation of the semantic averaging method proposed is that it is not always necessary. If at least one term exists denoting a novel phenomenon for a given (culturally-situated) observer, then of course it should simply be used. The process of searching for existing terms should first extend to other languages. If and only if a term exists neither in one's own nor other languages should semantic averaging be undertaken. This satisfies Occam's razor, where explanatory simplicity trumps superfluous

\footnotetext{
${ }^{25}$ Related to dual-process cogfective decision-making is the growing belief that System 1 affect is best understood in terms of "embodied, embedded" mental science [45]. Augmented psychology must test whether decision-making is augmented overall by the respective enactments of distinct types of embodiment (i.e., human vs. computer).
} 
complexity in scientific theorizing. It is more conscientious to mix two distinct ethnic languages before attempting to invent an entirely new term. ${ }^{26}$

Semantic averaging is also not the only method used to generate concepts. This is observed in the following generation and definition: conat (n.) - a volitional network; see cognit [65], which implies the redefinition of affect as a cardiac network. Conat follows from the existence of cognit and its derivation from cognition: conat has been similarly derived from conation.

Another consideration is defining which phenomena hybrid constructs might refer to. In the case of momeiohr, what-if anything - is it for both the past and future to exist simultaneously in a given mind? Two possibilities exist here. One is that any of cognition, affect, motivation, and behavior have intentionality in Brentano's sense (i.e., "aboutness" or pertinence). Said intentionality might be shared between two or more of these four facets of mind. Cognition's intentionality might pertain to the future, while affect's might pertain to the past: this could represent an example of cognitive-affective dissonance [47] and (in at least one sense) momeiohr. Another potential sense of momeiohr is thinking or feeling about, being motivated by, or acting in relation to the present, which exists temporally between the past (which memory focuses on) and future (the domain of foresight). In evaluating what a hybrid phenomenon like momeiohr is like, intentionality among the four factors of mind discussed can be considered in terms of dissonance or consonance between one another.

Related to the preceding sub-discussion is parsimony. Irrespective of novel concept generation, any of affect, cognition, motivation, or behavior can have shared or distinct intentionality within operation of the original, unitary construct (memory in momeiohr's case) or concept (foresight). One may think $X$ about the future but feel $Y$ about it. Both thinking and feeling $X$ about the past or future, if possible, could be spoken of as an example of cogfect, a phenomenon whose existence has been postulated in past work [11].

It is reasonable to doubt the necessity of momeiohr. While a theorist might find either memsight or foremory adequate, momeiohr defined as psychological intentionality of the present might seem overly similar to mindfulness. Mindfulness is an established construct in psychology [68] that is often defined as awareness of the present. Mindfulness is distinct from momeiohr in that the latter necessarily regards the present (being derived explicitly from the temporal constructs memory and foresight). Mindfulness is not necessarily of the present: one can also be mindful of the past or the future (and perhaps of both, though this is kept open). ${ }^{27}$

Phenomena like cogfect and momeiohr must be treated as speculative at this stage of psychological science. Evaluation of whether these concepts have internal or external validity is a project that might be best initiated in an introspective, intersubjective, and phenomenological manner. If two people believe strongly enough that they have

\footnotetext{
${ }^{26}$ In the case of blending memory and foresight, my study was confined to Western (Euro-American) psychology. No competing constructs to memory nor such concepts to foresight were found, though my study did not consider whether a term for momeiohr exists in any non-English language.

${ }^{27}$ Related is the common notion of intention as one's aim to carry out a task for $X$ purpose. Intentions of this kind are usually framed as conscious, but they can be unconscious or subconscious (and possibly superconscious) as well.
} 
experienced cogfect or momeiohr, then the more concrete defining of these phenomena could commence. Going even further, if two psycho-philosophers could communicate sincerely and truthfully that they have both, at any given point(s) of time $t$, experienced conation as motivated behavior or behavioral motivation (the former should be easy to agree on at this folk level), then they can move on to the more challenging notions of cogfect ${ }^{28}$ and momeiohr. In any case, it is advised that theorists interested in concept generation reflect critically before proposing novel concepts, for they can be erroneously termed or defined. An example of such a concept is confirmation neutrality [11], which was defined as seeking evidence to support only one's true beliefs. Defined this way, confirmation neutrality is really just a positive form of confirmation bias: it must be clarified as such, or the definition offered for the former concept should be revised as seeking evidence to support none of one's beliefs.

Proposed psychological laws 1-4 have not been derived empirically. Scientific laws must apply to general cases of phenomena. The four laws proposed in Section 4 have been intended as a priori axioms more appropriately considered as formal laws. Nonetheless, psycholawgy can (and, at this stage, should) be regarded as formal science at the nexus between analytic philosophy and theoretical psychology.

\section{Conclusion}

"Indivectivism" is an additional concept that is derivable from collectivism and individualism, two mainstay concepts in cultural psychology. Cognition can be augmented through a hybrid holistic-analytic (East-West) cognitive style situated within indivectivism. Inspiration for this concept arose from consideration of the characteristics of self-actualization as proposed by Maslow, particularly resolution of certain dichotomies and transcendence of one's culture. Terms introduced throughout this chapter have potential to not only contribute to augmented cognition, but may assist in the augmentations of consciousness, experience, culture [73], subjectivity, mind, and body as well.

Related to Section 4's proposal of a psycholawgy is a possible law that draws inspiration from physics' conservation of energy. Such a psychological law would be the "conservation of affect", stating that affect can be neither created nor destroyed. An example of this law in action is the fact that feelings often change: whether they can disappear forever or not would be an important hypothesis to test in assessing the speculated law. Much as matter is also conserved as well as energy, if the conservation of affect is found to hold, perhaps it could also apply for cognition or conation.

Continuing with physics: are entropy and gravity opponent forces? Gravitation binds low-mass objects to high-mass ones. Entropy is the scattering of matter and its conversion from such to energy. Gravity consists of gravitons; dark matter is speculated to

\footnotetext{
${ }^{28}$ In [11], intuition was defined as a term that is referred to in its psychological literature as affect and cognition in different places. It seems both more faithful and parsimonious to treat intuition less as cogfective (which was a compromise attempted in [11] given the divergence of how to conceive of intuition), and more as simply affective. If this is done, no concrete phenomenon will have yet been identified as being definitionally cogfective.
} 
make up entropy. If eventually discovered empirically, dark matter particles should be referred to as "entropons". This speculative discussion venturing into theoretical physics and cosmology follows from the proposal of wholicle as a novel concept for holarchic theory (which, via holarchic-informatic psychology, is related to human-computer interaction).

\section{References}

1. Wilber, K.: The Spectrum of Consciousness.

2. Csikszentmihalyi, M.: Flow: The Psychology of Optimal Experience. HarperCollins ebooks.

3. Seligman, M.: Authentic Happiness: Using the New Positive Psychology to Realize Your Potential for Lasting Fulfillment [Kindle DX version]. Simon \& Schuster, New York (2002)

4. Sood, S. (2019) The Psychoinformatic Complexity of Humanness and Person-Situation Interaction. In: Arai K., Bhatia R. (eds) Advances in Information and Communication. FICC 2019. Lecture Notes in Networks and Systems, vol 69. Springer, Cham

5. Sood S. et al. (2019) Holarchic Psychoinformatics: A Mathematical Ontology for General and Psychological Realities. In: Schmorrow D., Fidopiastis C. (eds) Augmented Cognition. HCII 2019. Lecture Notes in Artificial Intelligence, vol 11580. Springer, Cham

6. Hovhannisyan G., Henson A., Sood S. (2019) Enacting Virtual Reality: The Philosophy and Cognitive Science of Optimal Virtual Experience. In: Schmorrow D., Fidopiastis C. (eds) Augmented Cognition. HCII 2019. Lecture Notes in Computer Science, vol 11580. Springer, Cham

7. Festinger, L.: A Theory of Cognitive Dissonance. Stanford University Press, Stanford (1957)

8. Dijksterhuis, A. \& Strick, M.: A case for thinking without consciousness. Per. Psychol. Sci. 11(1), 117-132 (2015). https://www.researchgate.net/publication/292188707_A_Case_for_Thinking_Without_Consciousness. Accessed 19 Feb 2020

9. Gore, J., Sadler-Smith, E.: Unpacking intuition: A process and outcome framework. Rev. Gen. Psychol. 15(4), 304-316 (2011)

10. Kahneman, D.: Thinking, Fast and Slow [Kindle DX version]. Farrar, Straus and Giroux (2011)

11. Sood S. (2020) The Platonic-Freudian Model of Mind: Defining "Self" and "Other" as Psychoinformatic Primitives. In: Schmorrow D., Fidopiastis C. (eds) Augmented Cognition. Theoretical and Technological Approaches. HCII 2020. Lecture Notes in Computer Science, vol 12196. Springer, Cham. https://doi.org/10.1007/978-3-030-50353-6_6

12. Hume, D.: A Treatise of Human Nature. https://www.pitt.edu/ mmthompso/readings/hume.influencing.pdf. Accessed 1 Jul 2020

13. Covey, S. Moving from independence to interdependence. https://goskybound.com/independence-to-interdependence/. Accessed 1 Jul 2020

14. Gerlenter, D.: The Tides of Mind: Uncovering the Spectrum of Consciousness. Liveright, New York (2016)

15. Suddendorf, T.: Episodic memory versus episodic foresight: similarities and differences. WIREs Cog. Sci. 1, 99-107 (2010).

16. Zahavi, D: Self and Other: Exploring Subjectivity, Empathy, and Shame. Oxford University Press, Oxford (2014)

17. Neumann, S., Sood, S., Hollander, M., Wan, F., Ahmed, A., Hancock, M.: Using bots in strategizing group compositions to improve decision-making processes. In: Schmorrow, D., 
Fidopiastis, C. (eds.) Augmented Cognition 2018. LNCS, vol. 10916, pp. 305-325. Springer, Cham (2018)

18. Kelly, G.: Clinical Psychology and Personality: The Selected Papers of George Kelly. John Wiley \& Sons, New York (1969).

19. Revelle, W.: Integrating personality, cognition, and emotion: Putting the dots together? (2011). https://www.personality-project.org/revelle/publications/BPSP-revelle.pdf. Accessed 9 Jan 2019

20. Nagel, T.: What is it like to be a bat? Philos. Rev. 83(4), 435-50 (1974)

21. Horley, J.: The units of analysis problem in psychology: An examination and proposed reconciliation. In: Baker W.J., Mos L.P., Rappard H.V., Stam H.J. (eds.) Recent Trends in Theoretical Psychology. Recent Research in Psychology. Springer, New York (1989).

22. Lewin, K.: Field theory and experiment in social psychology: Concept and methods. Am. J. Soc. 44, 868-896 (1939)

23. Rauthmann, J., Sherman, R., Funder, D.: Principles of situation research: Towards a better understanding of psychological situations. Eur. J. Pers. 29, 363-381 (2015).

24. Bandura, A. \& Huston, A. C.: Identification as a process of incidental learning. J. Abnorm. Soc. Psych. 63(2), 311-318 (1961).

25. Plato: The Republic. ( ${ }^{\text {nd }}$ ed.). Penguin Books, London (2007). (Original Work Published in $\sim 375$ B.C.)

26. Kahneman, D.: Thinking, Fast and Slow. Farrar, Straus and Giroux [Kindle DX version] (2011)

27. Maslow, A. H.: A theory of human motivation. Psychol. Rev. 50, 370-96 (1943)

28. Maslow, A. H.: Toward a Psychology of Being. ( $1^{\text {st }}$ ed.). Wilder Publications, Blacksburg (2011). (Original Work Published in 1962)

29. Skinner, B. F.: Generic nature of the concepts of stimulus and response. J. Gen. Psychol. 12, 1240-1265 (1935)

30. Solipsism and the Problem of Other Minds. https://www.iep.utm.edu/solipsis/. Accessed 12 Nov 2019

31. Klein, S.: The self and science: Is it time for a new approach to the study of human experience? Curr. Dir. Psychol. Sci. 21(4), 253-57 (2012).

32. Dennett, D. C.: The self as a center of narrative gravity. In: F. Kessel, P. Cole, \& D. Johnson (eds.) Self and Consciousness: Multiple Perspectives. Erlbaum, Hillsdale (1992)

33. Zahavi, D: Self and Other: Exploring Subjectivity, Empathy, and Shame. Oxford University Press, Oxford (2014)

34. Buber, M.: I and Thou. (1958)

35. Gerbasi, M. E., Prentice, D. A.: The Self- and Other-Interest Inventory. J. Pers. Soc. Psychol. 105(3), 495-514 (2013).

36. Maslow, A. H.: Religions, Values, and Peak-experiences. Penguin Compass: New York. (1976)

37. Velkley, R.: Freedom and the Human Person. Catholic University of America Press: Washington, D.C. (2007)

38. Spalding, T., Stedman, J., Gagné, C. L., Kostelecky, M.: The Human Person: What Aristotle and Thomas Aquinas Offer Modern Psychology. Springer International Publishing (2019)

39. DeYoung, C.G., Weisberg, Y.J., Quilty, L.C., Peterson, J.B.: Unifying the aspects of the Big Five, the interpersonal circumplex, and trait affiliation. J. Pers. 81(5), 465-475 (2013)

40. Brand, R. J., Rosenman, R. H., Sholtz, R. I., Friedman, M.: Multivariate prediction of coronary heart disease in the Western collaborative group study compared to the findings of the Framingham study. https://pubmed.ncbi.nlm.nih.gov/1245042/. Accessed 6 Jul 2020 
41. Shouse, E.: Feeling, emotion, affect. M/C J. 8(6) (2005). http://journal.media-culture.org.au/0512/03-shouse.php. Accessed 18 Nov 2019

42. Patterson, R. E., Eggleston, R. G.: Intuitive cognition. J. Cog. Eng. Decis. Mak. 11(1), 5-22 (2017). https://www.deepdyve.com/lp/sage/intuitive-cognition-fdpCmqLtLc?key=sage

43. Mischel, W., Shoda, Y.: A cognitive-affective system theory of personality: Reconceptualizing situations, dispositions, dynamics, and invariance in personality structure. Psychol. Rev. 102(2), 246-268 (1995).

44. Arisaka, Y.: 'Self and other' in Japanese philosophy. In: E. Thompson (ed.) Between Ourselves: Second-Person Issues in the Study of Consciousness. Imprint Academic, Thorverton (2001)

45. Bellini-Leite, S. d. C.: The embodied embedded character of System 1 processing. https://www.ncbi.nlm.nih.gov/pmc/articles/PMC3653224/. Accessed 20 Aug 2020

46. Hazony, Y.: Domain-general operations in the mind's 'central processing system'? A test case for psycho-ontology. https://www.psychoontology.org/docs/yoram-hazony.pdf. Accessed 22 Aug 2020

47. Marshall, S.: Cognitive-affective dissonance in the classroom. https://www.tandfonline.com/doi/abs/10.1080/00922013.1980.11000222. Accessed 22 Aug 2020

48. Varela., F., Thompson, E., Rosch, E.: The Embodied Mind: Cognitive Science and Human Experience. The MIT Press, Cambridge, MA (1991).

49. Thompson, E.: Between Ourselves: Second-Person Issues in the Study of Consciousness. Imprint Academic, Thorverton (2001).

50. Varela, F., Shear, J.: The View from Within: First-Person Approaches to the Study of Consciousness. Imprint Academic, Thorverton (1999).

51. Lycan, W. G.: Consciousness and Experience. The MIT Press, Cambridge, MA (1996).

52. Kukla, A.: Methods of Theoretical Psychology. The MIT Press, Cambridge, MA (2001).

53. Searle, J.: The Mystery of Consciousness. New York Review Books, New York (1997)

54. Wilber, K.: Sex, Ecology, Spirituality: The Spirit of Evolution. Shambhala Publications, Boston (2000).

55. https://en.wikipedia.org/wiki/Affective_spectrum\#: :text=The\%20affective\%20spectrum\%20is\%20a,than\%20would\%20normally\%20be\%20expected. Accessed 11 Sept 2020

56. https://en.wikipedia.org/wiki/Virtual_community_of_practice. Accessed 12 Sept 2020

57. Wrenn, M. V., Waller, W.: Care and the neoliberal individual. https://www.tandfonline.com/doi/abs/10.1080/00213624.2017.1321438?journalCode=mjei20. Accessed 13 Sept 2020

58. Cornelius, R. R.: The Science of Emotion: Research and Tradition in the Psychology of Emotions. Prentice Hall, New Jersey (1996).

59. Sternberg, R. J.: A triangular theory of love. Psychol. Rev. 93(2), 119-135 (1986).

60. Lamiel, J. T.: Toward an idiothetic psychology of personality. Amer. Psychol. 36(3), 276289 (1981).

61. Osbeck, L. M., Nersessian, N. J.: Epistemic identities in interdisciplinary science. Perspect. Sci. 25(2), 226-260 (2017).

62. Huang, J., Huhns, M. N.: Superconcept formation system—An ontology matching algorithm for service discovery. https://cse.sc.edu/ huhns/confpapers/sd06-huang-v2.pdf. Accessed 7 Oct 2020

63. https://www.abandonment.net/. Accessed 7 Oct 2020

64. Scalambrino, F.: Philosophical Principles of the History and Systems of Psychology: Essential Distinctions. Springer, New York (2018).

65. https://www.yourdictionary.com/cognit. Accessed 8 Oct 2020 
66. https://arxiv.org/ftp/arxiv/papers/1604/1604.06158.pdf. Accessed 14 Oct 2020

67. Abel, C.: The Extended Self: Architecture, Memes, and Minds. Manchester University Press, U.K. (2015).

68. Langer, E. J.: Mindfulness, $25^{\text {th }}$ Anniversary edn. Da Capo Press, Boston, MA (2014). (Original Work Published in 1989)

69. Fromm, E.: The Art of Being. Open Road, New York, NY (2013).

70. https://www.healthyway.com/content/type-c-and-d-two-unique-often-overlooked-personality-types/. Accessed 14 Oct 2020

71. https://become-hub.com/en/\#: :text=Augmented\%20Psychology\%20is\%20an\%20innovative,last\%20frontiers\%20of\%20neuroscientific\%20research. Accessed 9 Nov 2020

72. Seligman, M.: Learned helplessness. https://www.annualreviews.org/doi/pdf/10.1146/annurev.me.23.020172.002203. Accessed 9 Nov 2020

73. https://newprairiepress.org/oz/vol33/iss1/7/. Accessed 9 Nov 2020

74. Maki, R. H., McCaul, K. D.: The effects of self-reference versus other reference on the recall of traits and nouns. Psychon. Bull. Rev. 23(3), 169-172 (1985). 